\title{
Phytochemical and Antimicrobial Assessment of Five Medicinal Plants Found in Terai Region
}

\author{
Sadhana Sah, Ranjita Shrestha, Sadikchya Koirala and Keshab Bhattarai \\ Department of Biotechnology, White House Institute of Science \& Technology \\ Khumaltar, Lalitpur \\ e-mail: keshab.bhattrai@gmail.com
}

\begin{abstract}
Crude petroleum ether and methanol extracts of different parts of five medicinal plants collected from Terai region, namely, Asparagus racemosus, Catharanthus roseus, Hedychium coronarium, Mimosa pudica and Terminalia chebula were examined for their antimicrobial activity against different pathogenic microorganisms, Staphylococcus aureus, Escherichia coli, Klebsella spp., Salmonella paratyphi, Bacillus subtilis, Aspergillus niger, Fusarium spp. and Penicillium spp. From the obtained growth curves of methanol extract of Terminalia chebula and petroleum ether and methanol extracts of Hedychium coronarium, it can be said these extracts have relatively high bacteriostatic property than other plant extracts. Similarly, the zone of inhibitions observed during antifungal assay by methanol extract of Terminalia chebula against Aspergillus niger, Fusarium spp. and Penicillium spp. are comparable to that of Itraconazole (antifungal drug). It shows that Terminalia chebula has fungistatic property. Phytochemical screening revealed the presence of alkaloids, coumarins, flavonoids, terpenoids, steroids and glycosides.
\end{abstract}

Key words: bacteriostatic, crude extracts, fungistatic, growth curves, thin layer chromatography

\section{Introduction}

Plants produce a huge array of different types of chemicals. Humans exploit these chemicals for a huge range of applications such as for drugs, flavors, fragrances etc. Nature has a rich reservoir of plants from which such structurally diverse chemical compounds can be extracted. Such diverse compounds include terpenoids, steroids, fatty acid-derived substances, polypeptides, alkaloids, non-ribosomal polypeptides and enzyme cofactors which are classes of secondary metabolites. These secondary metabolites are synthesized during adaptation to environmental stress and they have been exploited to get useful medicines to fight against diseases (Gupta 1994). This research has focused on phytochemical and antimicrobial properties of five different medicinal plants chosen on the basis of their availability and their medicinal values are Asparagus racemosus, Catharanthus roseus, Hedychium coronarium, Mimosa pudica and Terminalia chebula. Which were collected from Barahathawa, Sarlahi.
A. racemosus (family Asparagaceae) is locally known as Satawar. It is a shurb distributed $(100-2100 \mathrm{~m})$ east to west in Nepal having small leaves, linear with small stout spinous spur at the base. Its fruits are globose (3-5mm) in diameter and turn bright red when ripened. It is fairly common in wild and gardens. The extracts of different parts of it are used as tonic, galactogogue and appetizer. The other uses of plants are in diuretic, aphrodisiac, tuberculosis, cough, and diarrhea (Kirtikar \& Basu 1975). The major components reported from rhizome are carbohydrates, cardioglycosides, saponins, oils, fats, steroids, sterols, flavonoids, tannins, phenolic compounds and amino acids (Tenmozhi et al. 2010).

C. roseus (family Apocynaceae) is commonly known as Sadabahar, Nayantara, Sadaphal, Ainshakti, Pillaganneru, etc. It is a herb distributed (150-1500m) east to west in Nepal with a height about $1 \mathrm{~m}$. The leaves are ovate in shape. Flowers are found in axillary clusters of 2-3; petals are white with pink color and are 
found throughout the years. The fruits are follicular. The juice of the leaves is beneficial in wasp-stings and menorrhagia. The roots are used as tonic and the major components reported are triterpenoids, tannins and alkaloids (Nayak \& Pereira 2006).

$H$. coronarium (family Zingiberaceae) is commonly known as Dudh Kevara, which it is perennial, (1-1.5m) tall rhizomatous herb distributed (1500-2100m) east to west in Nepal. The leaves are simple, alternate, sheathed base and flowers are pure white with fragrance. The rhizomes are bitter and the major components reported from them are starch, albumin, alkenes, organic acids, essential oils, resins and diterpenes (Nakatani et al. 1994). The rhizome extracts have shown anti-inflammatory, analgesic (Shrotriya et al. 2007), antihypertensive (Ribeiro et al. 1986), diuretic (Ribeiro et al. 1988), leishmanicidal and antimalarial activities (Valadeau et al. 2009).

M. pudica (family Fabaceae) is commonly known as Lajjawanti and Buharijhar. This under-shrub is distributed (200-1200m) east to west in Nepal and recognized by its prickly hairy stems and sensitive leaves. The leaves are pinnate with four pinnae arranged palmately. Flowers are globose heads with purplish-pink in colour. Fruits are globular in clusters. The leaves and roots are useful in diseases of kidneys, piles and fistula. The roots are used in the treatment of asthma, fever, cough, dysentery, vaginal and uterine ailments and the major components reported are alkaloids, flavonoids, glycosides, triterpenes and saponin (Parekh \& Chanda 2007).

T. chebula (family Combretaceae) is commonly known as Harro. It is a moderate sized tree distributed (150$1100 \mathrm{~m}$ ) east to west in Nepal. Leaves are simple, opposite, stalked and elliptic oblong. Flowers are yellowish white in terminal spikes. Fruits are drupes, yellow to orange brown. The fruits are used as tonic, to enrich blood, against diseases of spleen, piles, cold and for strengthening brain, eyes and gums. The major components reported in fruit extracts are triterpenoids, coumarin, tannin and phenolic compounds (Racadio et al. 2008). The fruit extracts are used in the treatment of asthma, sore throat, vomiting, hiccough, bleeding, piles, diarrhoea, gout, heart and bladder diseases and have shown antioxidant properties (Cheng et al. 2003), anticancer agents (Husheem et al. 2002), antidiabetic
(Kirtikar \& Basu 1935) and antimicrobial activities (Kumar et al. 2009). The biologically active compounds of this plant from petroleum extract are glycosides whereas methanol extract showed the presence of alkaloids, tannins, flavonoids, steroids, saponins and carbohydrate (Jayalaxmi et al. 2011).

\section{Methodology \\ Plant materials}

Five different medicinal plants $A$. racemosus, C. roseus, $H$. coronarium, M. pudica and T. chebula were collected from Barahathawa, Sarlahi as they were locally and easily available in most of the parts of this village. Different parts of plants used for the phytochemical and antimicrobial analysis were: tubers (A. racemosus), whole parts (C. roseus), rhizomes $(H$. coronarium), whole parts (M. pudica) and fruits ( $T$. chebula)

\section{Plant extraction}

The plant parts were air dried, chopped, grinned and extracted for several hours with petroleum ether and methanol (cold extraction) in order to obtain non-polar to polar portion from the plant materials. Organic solvents were removed separately from each of these extracts under reduced pressure using rotavapour. Yield of each extract was calculated by the following formula:

$$
\text { Yield }(\%)=\frac{\text { Weight of extract }}{\text { Total weight of sample }} \times 100
$$

\section{Phytochemical screening}

Phytochemical screening was done in order to find the presence of the active chemical constituents such as alkaloids, steroids, flavonoids, reducing sugars, tannins, etc. The crude petroleum ether and methanol extracts of the plants were analyzed using standard phytochemical methods (Harborne 1998, Aguinaldo et al. 2005)

\section{Thin layer chromatography}

Methanol and petroleum ether extracts of the test plants were checked on thin layer chromatography (TLC) using different solvent system of varying polarity: Petroleum ether/Ethyl acetate (95:5), Petroleum ether/ Ethyl acetate (90:10), Petroleum ether/Ethyl acetate (80:20), Chloroform/Methanol (95:5) and Chloroform/Methanol (90:10). TLC plates were then observed through UV, Iodine, $5 \% \mathrm{H}_{2} \mathrm{SO}_{4}, \mathrm{FeCl}_{3}$ and Dragendroff's tests. 


\section{Antimicrobial Assay}

Agar- well diffusion method

The solvents free petroleum ether and methanol extracts of $A$. racemosus, $C$. roseus, $H$. coronarium, $M$. pudica and $T$. chebula were tested against different pathogenic bacteria and fungi strains such as $S$. aureus, E. coli, Klebsella spp., S. paratyphi, B. subtilis, A. niger, Fusarium spp. and Penicillium spp. obtained from the Microbiology Laboratory, White House Institute of Science and Technology, Khumaltar, Lalitpur. These bacterial strains are selected as representative organisms for pathogenic Gram positive and Gram negative bacteria. The fungal cultures were used as per availability and their pathogenic natures. The concentration used was $1 \mathrm{mg} / \mathrm{ml}$. Bacterial inoculums were prepared in nutrient broth by taking loop full of organisms and incubating them at $37^{\circ} \mathrm{C}$ for $24 \mathrm{hr}$. Fungal inoculums were prepared in Potato Dextrose Broth by taking few spores and incubating them at $25^{\circ} \mathrm{C}$ for $72 \mathrm{hr}$. The antimicrobial activity was assayed by measuring the diameter of the inhibition zone formed around the well. The effects of different extracts of all the samples on microorganisms were then studied and their zones of inhibitions were compared taking Streptomycin as standard for antibacterial assay and Itraconazole as standard for antifungal assay.

\section{Microtitration method}

Methanol and petroleum ether extracts of $A$. racemosus, $C$. roseus, $H$. coronarium, $M$. pudica and T. chebula were tested for their property to inhibit the growth pattern of pathogenic bacteria. Streptomycin stock $(1 \mathrm{mg} / \mathrm{ml})$ was prepared in phosphate buffer saline (PBS) and filtered through $0.45 \mu \mathrm{m}$ syringe filter and stored at $-20^{\circ} \mathrm{C}$. Broth culture of bacterial strain $(500 \mu \mathrm{l})$ was transferred into $5 \mathrm{ml}$ of freshly prepared sterile brain heart infusion broth (BHIB) which was then dispensed into 96 well plates along with filter sterilized solution of the plants extracts with final volume of $200 \mu \mathrm{l}$ in each well. Absorbance was taken at $630 \mathrm{~nm}$ using microplate reader and data were retrieved using a printer for 9 hours at an interval of $1 \mathrm{hr}$. Freshly, prepared sterile broth was also dispensed in some wells as natural control.

\section{Results and Discussion}

\section{Extraction yields}

The yield (\%) of extracts was between 0.22 14.92percent. It was higher for methanol extraction than petroleum ether extraction indicating the presence of more polar fraction (Table 1).

Table l. Extraction values of five plants in different solvents

\begin{tabular}{c|c|c} 
Plants & Solrents & Extract yield (\%) \\
\hline A racemosus & Petroleum ether & 0.28 \\
& Methanol & 5.83 \\
C. roseus & Petroleum ether & 0.38 \\
& Methanol & 2.89 \\
H. coronarium & Petroleum ether & 1.46 \\
& Methanol & 5.47 \\
M. pridica & Petroleum ether & 0.22 \\
& Methanol & 1.8 \\
T. chebula & Petroleum ether & 0.27 \\
& Methand & 14.92 \\
\hline
\end{tabular}

\section{Phytochemical screening}

Phytochemical screening of the crude petroleum ether and methanol extracts of the five plants revealed the presence of different bioactive compounds (Table 2). Alkaloids were detected in petroleum ether and methanol extracts of $H$. coronarium, $M$. pudica and $T$. chebula whereas reducing sugars were observed in all cases. Terpenoids and steroids were also present in most of the extracts.

Alkaloids have bio-medicinal properties and used as actual drugs in pharmaceutical industry (Cordell 1981). Terpenes are valued for the presence of aromatic fragnance (Turner 1970), essential oils (Kovat 1987), etc. There is evidence that some of the phytosterols are effective against cardiovascular disease (KrisEtherton et al. 2002). Presence of saponin means the plant has the detergent properties and piscidal property (Hostettman \& Marston 1995).

\section{TLC analysis}

The TLC behavior of different crude extracts in different solvent systems showed the presence of compounds of different polarity. TLC of petroleum ether extract of $H$. coronarium in the solvent system petroleum ether/ethyl acetate (90:10) showed the 
presence of 2-3 spots of alkaloids after spraying of Dragendroff's reagent (orange color appearance) having $\mathrm{Rf}=0.66,0.3 \& 0.2$. Similarly the appearance of orange color after spraying with Dragendroff's reagent in extracts of M. pudica and T. chebula indicated the presence of alkaloids.

Table 2. Result of the phytochemical test

\begin{tabular}{c|c|c|c|c|c|cc|c|c|c}
\hline \multirow{2}{*}{ Phytochemicals } & \multicolumn{2}{|c|}{ A racemosus } & \multicolumn{2}{|c|}{ C. roseus } & \multicolumn{2}{c|}{ H. coronarium } & \multicolumn{2}{c|}{ M. pudica } & \multicolumn{2}{c}{ T. chebula } \\
\cline { 2 - 11 } & Pet & Met & Pet & Met & Pet & Met & Pet & Met & Pet & Met \\
\hline Alkaloids & - & - & - & - & + & + & + & + & + & + \\
Glycosides & - & + & - & - & - & + & - & - & - & + \\
Terpenoids & + & + & + & + & - & - & + & - & + & + \\
Steroids & + & - & + & + & - & - & + & + & + & - \\
Flawonoids & - & - & - & - & - & - & - & + & - & - \\
Reducing sugars & + & + & + & + & + & + & + & + & + & + \\
Courn arins & - & - & - & - & - & - & - & + & + & + \\
Tanrins & - & - & - & - & - & - & - & - & - & - \\
Saporins & - & + & - & - & + & - & - & - & + & + \\
\hline
\end{tabular}

Pet: Petroleum ether, Met: Methanol. (+) and (-) signs indicate the presence and absence of phytochemicals respectively.

The spots on TLC of M. pudica and T. chebula extracts gave intense violet color, orange color, brick red spot while heated after spraying with $5 \%$ sulphuric acid. These indicate the presence of different terpenoids in the extracts and also confirmed by Liebermann Burchard test.

Thus, TLC is applicable for the detection of different chemical compounds. It is also useful in the separation of the pure compound according to its Retention factor value $\left(\mathrm{R}_{\mathrm{f}}\right)$.

Table 3. Zone of inhibitions of petroleum ether and methanol extracts of different plants on different pathogenic microbes

\begin{tabular}{|c|c|c|c|c|c|c|}
\hline \multirow[t]{3}{*}{ Plant/Standard } & \multirow[t]{3}{*}{ Extract } & \multicolumn{5}{|c|}{ Zone of inhibition (mm) } \\
\hline & & \multicolumn{2}{|c|}{ Gram positive bacteria } & \multicolumn{3}{|c|}{ Gram negative bactaria } \\
\hline & & B. subtilis & S. aureus & E. coli & Klebsella spp. & S. paratyphi \\
\hline \multirow[t]{2}{*}{ A. racemosus } & $\begin{array}{c}\text { Petrole um } \\
\text { ether }\end{array}$ & 8 & - & - & 8 & - \\
\hline & Methanol & 13 & - & - & 8 & - \\
\hline \multirow[t]{2}{*}{ C. roseus } & $\begin{array}{l}\text { Petroleum } \\
\text { ether }\end{array}$ & 12 & - & - & - & 15 \\
\hline & Methanol & 14 & - & - & 12 & 12 \\
\hline \multirow[t]{2}{*}{ H. coronarium } & $\begin{array}{l}\text { Petrole um } \\
\text { e ther }\end{array}$ & 21 & 16 & - & 13 & 16 \\
\hline & Methanol & 17 & 10 & - & 12 & - \\
\hline \multirow[t]{2}{*}{ M. pudica } & $\begin{array}{l}\text { Petroleum } \\
\text { e ther }\end{array}$ & 9 & - & - & 8 & - \\
\hline & Methanol & 11 & 9 & - & 8 & 16 \\
\hline \multirow[t]{2}{*}{ T. chebula } & $\begin{array}{l}\text { Petrole um } \\
\text { ether }\end{array}$ & 10 & - & - & 7 & - \\
\hline & Methanol & 15 & 15 & 15 & 14 & 15 \\
\hline Stre ptomycin & - & 29 & 12 & - & 16 & 12 \\
\hline Control & - & - & - & - & - & - \\
\hline
\end{tabular}

\section{Antimicrobial assay \\ Antibacterial properties}

The zone of inhibitions shown by petroleum ether extract of $H$. coronarium and methanol extract of $T$. chebula against $B$. subtilis, S. aureus, Klebsella spp. and $S$. paratyphi were comparable to that of streptomycin. E. coli was found to be resistant to all the samples except methanol extract of T. chebula. $S$. paratyphi was sensitive to most of the extracts (Table $3)$. The alteration of growth patterns of tested microorganisms, E. coli, Klebsella spp., S. aureus, S. 
paratyphi and $B$. subtilis might be due to the bacteriostatic property of respective extracts incorporated with them. From the obtained growth curves of methanol extract of $T$. chebula and petroleum ether and methanol extracts of $H$. coronarium (Fig.1Fig.8); it can be said that these extracts have relatively

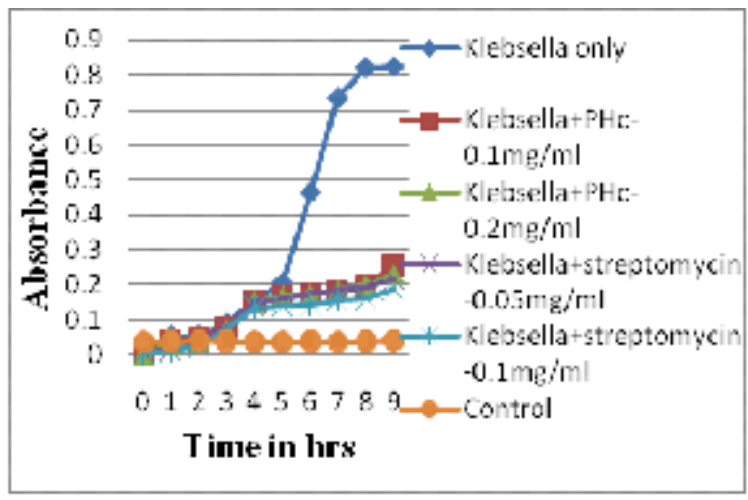

Fig. 1. Fifect of $H$ coromanion petrolem ether extract on Nebsellasp.

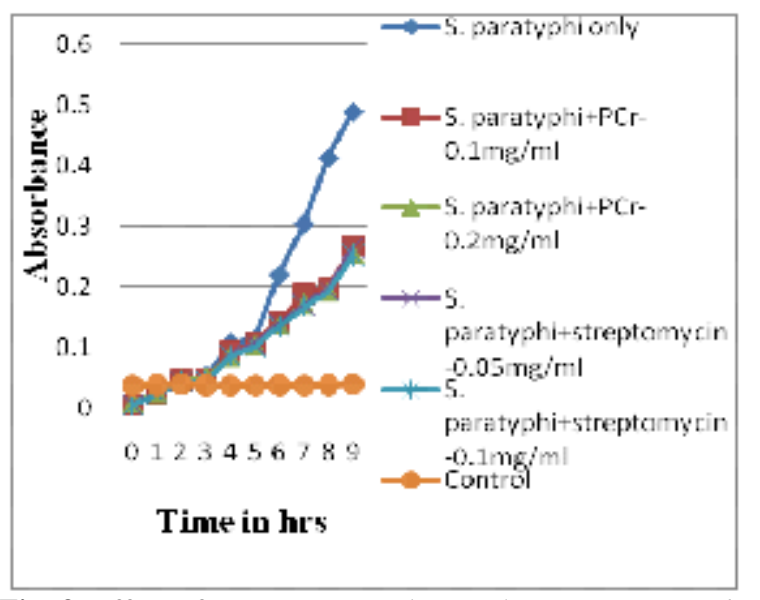

Fig. 3. Effect of C. roseus petroleum ether on S. paratyphi

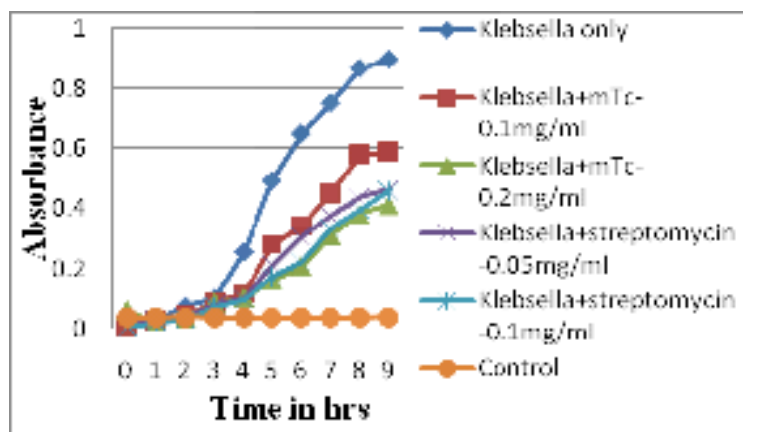

Fig. 5. Effect of T. chebula methanol extract on E. coli high bacteriostatic property than other extracts. The antimicrobial activity showed that methanol extract of T. chebula and petroleum ether and methanol extracts of $H$. coronarium have relatively high antibacterial property which may be due to the presence of bioactive compounds present in the extracts.

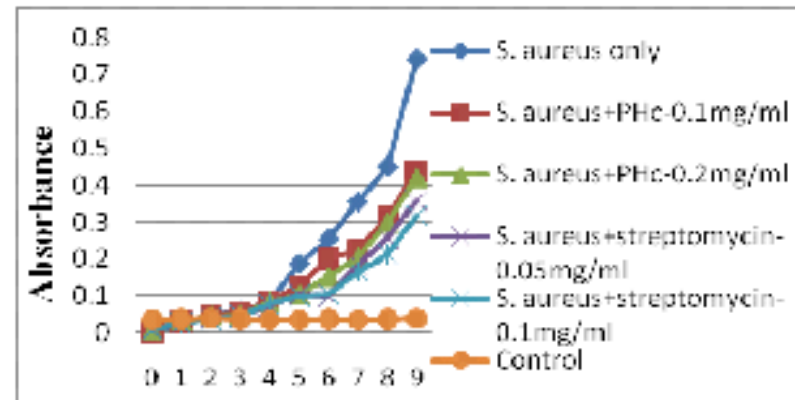

I inue in brs

Fig. 2. Efifect of $H$ coronarison petrolemm ether extract on $S$ augeus

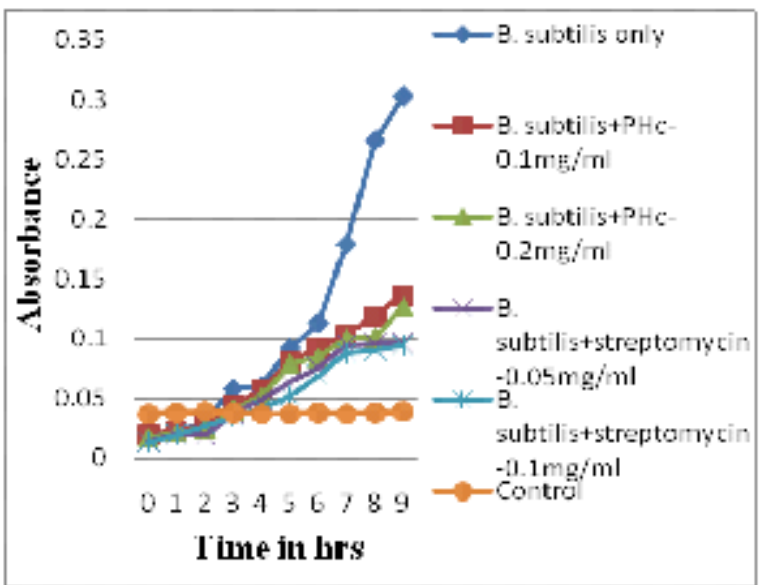

Fig. 4. Effect of $H$. coronarium petroleum ether extract on $B$. subtilis

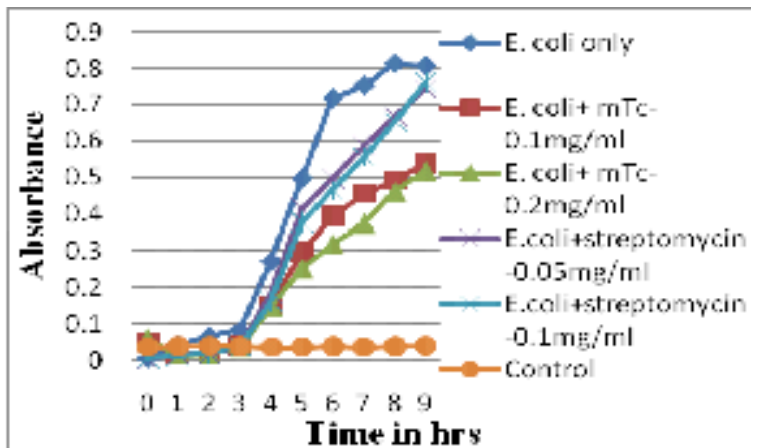

Fig. 6. Effect of T. chebula methanol extract on Klebsella spp. 


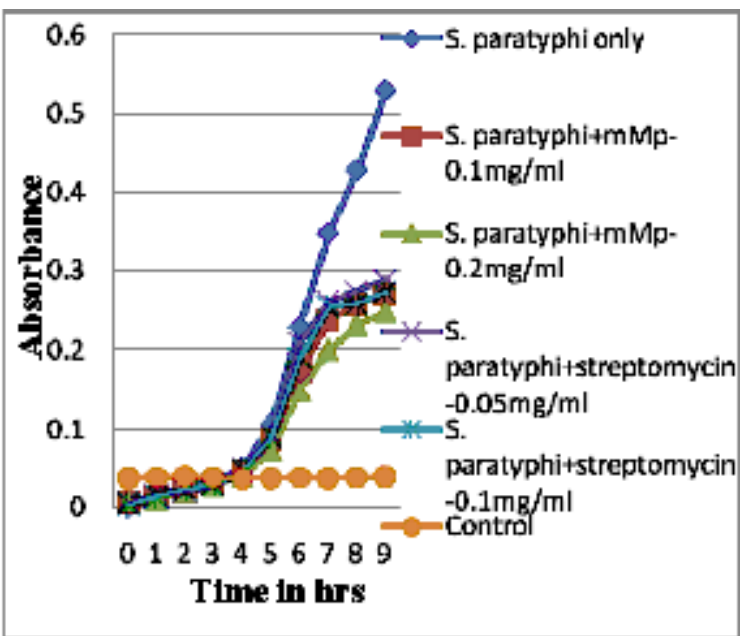

Fig. 7. Effect of M. pudica methanol extract on S. paratyphi

\section{Antifungal properties}

The zone of inhibitions (Table 4) shown by methanol extract of $T$. chebula against $A$. niger, Fusarium spp. and Penicillium spp. were comparable to that of

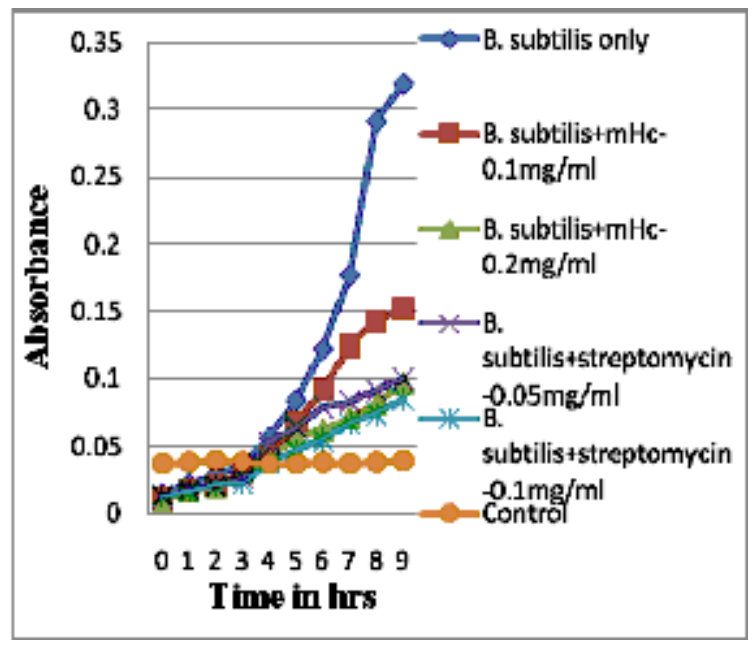

Fig. 8. Effect of $H$. coronarium methanol extract on $B$. subtilis

Itraconazole (antifungal drug). It shows that T. chebula has fungistatic property due to the presence of bioactive compounds like: alkaloids, terpenoids and coumarins.

Table 4. Zone of inhibitions of petroleum ether and methanol extracts of different plants on different fungi

\begin{tabular}{|c|c|c|c|c|}
\hline \multirow[t]{2}{*}{ Plant' Standard } & \multirow[t]{2}{*}{ Extract } & \multicolumn{3}{|c|}{ Zone of inlubition ( $\mathrm{mm}$ ) } \\
\hline & & Aspergilus niger & Fusarium spp. & Penicillium spp. \\
\hline A Racemosis & Petroleum ether & - & - & - \\
\hline & Methanol & - & - & - \\
\hline C roseus & Petroleum ether & - & - & - \\
\hline & Methanol & - & - & - \\
\hline$H$ cononarium & Petroleum ether & - & - & - \\
\hline & Methanol & - & - & - \\
\hline M. pudica & Petroleum ether & - & - & - \\
\hline & Methanol & - & - & - \\
\hline T.chebula & Petroleum ether & - & - & - \\
\hline & Methanol & 13 & 15 & 13 \\
\hline Itraconazole & - & 13 & - & - \\
\hline Control & - & - & - & - \\
\hline
\end{tabular}

Different bioactive compounds such as, alkaloids, coumarins, flavonoids, terpenoids, steroids, reducing sugars, saponins and glycosides were successfully identified. Their antimicrobial activities were found satisfactory. However, the commercial production of these compounds is still far away. The main problem is due to the lack of optimization of cultural conditions and several strategies leading with increased accumulation of secondary metabolites. Detail studies are required to know the proper enzyme functions at various levels, product membrane permeability and adsorption for improvements towards achieving a viable economic production methodology. In addition, over-expression of enzymes and the genetic modification could be very useful via organogenesis or somatic embryogenesis for the production of desired levels of secondary metabolites.

\section{Acknowledgements}

We are grateful to the Department of Biotechnology, White House College for providing us with the necessary laboratory facilities for our work. 


\section{References}

Aguinaldo, A.M., E.I. Espeso, B.Q. Guevara and M.G. Nonato. 2005. A guidebook to plant screening: Phytochemical and Biological (Ed. B.Q. Guevara). Manila University of Santo Thomas Press, The Philippines.

Cheng, H.Y., T.C. Lin, K.H. Yu, C.M. Yang and C.C. Linn. 2003. Antioxidant and free radical screening activities of Terminalia chebula. Bio. Pharm. Bull. 26: 13311335.

Cordell, G. 1981. Introduction to Alkaloids: A Biogenetic Approach. Wiley and Sons, New York.

Gupta, S.S. 1994. Prospects and perspectives of natural plant products in medicine. Ind. J. Pharmacol. 26.

Harborne, J.B. 1998. Phytochemical methods. Chapman and Hall, London. 7-8pp.

Hostettman, K. and A. Marston. 1995. Saponins. Cambridge University Press, United Kingdom.

Husheem, S.M., P. Harkonen and K. Pihlaja. 2002. Inhibition of cancer cell growth by crude extract and the phenolics of Terminalia chebula Retz. Fruit. J. Ethnopharmacol. 81: 327336.

Jayalaxmi, B., K.A. Raveesha and K.N. Amruthesh. 2011. Phytochemical investigations and antibacterial activity of some medicinal plants against pathogenic bacteria. $J$. Appl. Pharmaceut. Sci. 2 (5): 124-128.

Kirtikar, K.R. and B.D. Basu. 1935. Indian Med. Plant. L.M. Basu, Allahabad. 1020 1023pp.

Kirtikar, K.R. and B.D. Basu. 1975. Indian Med. Plants. Dehradun, India. 2499-2500pp.

Kovat, E. 1987. Composition of essential oils, part 7. Bulgarian oil of rose (Rosa damascena Mill.). J. Chromatogr. A 406: 185-222.

Kris-Etherton, P.M., K.D. Hecker, A. Bonanome, S.M. Coval, A.E. Binkoski, K.F. Hilpert, A.E. Griel and T.D. Etherton. 2002. Bioactive compounds in foods: their role in the prevention of cardiovascular disease and cancer. Am. J. Med. 113 (Suppl 9B): 71S-88S.

Kumar, M., R.C. Agarawal, S. Dey, V.K. Rai and B. Johnson. 2009. Antimicrobial activity of aqueous extract of Terminalia chebula Retz. on gram-positive and gramnegative microorganisms. Int'l. J. Curr. Pharmaceut. Res. 1 (1): 56-60.
Nakatani, N., H. Kikuzaki, H. Yamaji, K. Yoshio, C. Kitora, K. Okada and W.G. Padolina. 1994. Labdane diterpenes from rhizomes of Hedychium coronarium. Phytochemistry. 37: 1383-1388.

Nayak, B.S. and L.M.P. Pereira. 2006. Catharanthus roseus flower extract has wound-healing activity in Sprague Dawley rats. BML Complementary and Alternative Medicine 6: 41.

Parekh, J. and S. Chanda. 2007. Antibacterial \& Phytochemical Studies on Twelve Species of Indian Medicinal Plants. African Journal of Biomedical Research 10: 175-181.

Racadio, S.P., G.V. Molina and R. Tacla. 2008. Phytochemical and microbial testing of Makahiya (Mimosa pudica Linn.) leaf extract. UNP Res. J. XVII: 11-18.

Ribeiro, R.A., M.M.F. DeMelo, F. DeBarros, C. Gomes and G. Trolin. 1986. Acute antihypertensive effect in conscious rats produced by some medicinal plants used in the state of São Paulo. J. Ethnopharmacol. 15 (3): 261-269.

Ribeiro, R.A., M.M.F. DeMelo, F. DeBarros, C. Muniz, S. Chieia, M.G. Wanderley, C. Gomes and G. Trolin. 1988. Acute diuretic effects in conscious rats produced by some medicinal plants used in the state of São Paulo. J. Ethnopharmacol. 24 (1): 19-29.

Shrotriya, S., M.S. Ali, A. Saha, S.C. Bachar and M.S. Islam. 2007. Anti-inflammatory and analgesic effects of Hedychium coronarium Koen. Pak. J. Pharma. Sci. 20 (1): 47-51.

Tenmozhi, M., R. Sivaraj and H.R. Yadav. 2010. A comparative phytochemical analysis of Alstonia scholaris, Lawsonia inermis, Ervatamia divaricata and Asparagus racemosus. Int'l. J. Pharma. 2(9): 86-91.

Turner, A. 1970. Terpenoids and steroids. Annu. Rep. Prog. Chem. Sect. B: Org. Chem. 66: 389-411.

Valadeau, C., A. Pabon, E. Deharo, J. Albán-Castillo, Y. Estevez, F.A. Lores, R. Rojas, D. Gamboa, M. Sauvain, D. Castillo and G. Bourdy. 2009. Medicinal plants from the Yanesha (Peru): Evaluation of the leishmanicidal and antimalarial activity of selected extracts. J. Ethnopharmacol. 123 (3): 413-422. 
Nepal Journal of Science and Technology Vol. 13, No. 2 (2012) 79-86 